\title{
ARTICLES
}

\section{Using the INTERNET as a Professional Development Tool: An Analysis}

\author{
by Vivienne Monty and P. Warren-Wenk
}

\begin{abstract}
This article provides an overview of the concepts and practice of prof essional development in library and information science, and studies the way in which professional development is changing with the advent of the Internet. The authors suggest that the incorporation of networking activities into the working lives of librarians is producing fundamental changes in the process of professional development. The article suggests ways in which electronic sources can be used to replace or enhance traditional modes of professional development, and concludes with a selection of specific Internet resources of interest to education librarians for professional development.
\end{abstract}

\section{Professional Development: Definitions and Background}

The literatures of management, sociology, and psychology agree that professional development is critical to job satisfaction. Indeed, of the many job-related variables studied, only professional development consistently differentiates those who are more satisfied with their jobs from those who are less so. (Penn, Romano, Foat, 1988)

In library and information science, professional development has become a common buzzword. Nevertheless, our profession has not yet devised a standard definition of professional development, nor has it outlined a modus operandi to pursue in order to attain professional growth. What the library and information science literature lacks in substantive material, it makes up for in an abundance of lists and descriptions of professional development activities for librarians. Theory and practice are rarely combined, and studies to date do not suggest concrete avenues for the practitioner to follow.

Two definitions of professional development follow:

1) the study and practice of enhancing the learning capacity through the development and application of learning-based interventions for the purpose of optimizing human and organizational growth and effectiveness (Chalofsky, 1992); and

2) "a range of activities aimed at developing and enhancing knowledge, skills and attitudes...[which] prepares the individual to carry out his or her job in the most effective manner, but also heightens motivation, and contributes to the individual's longer term progress and achievement." (Webb, 1992, p. 14)

People may seek to get involved in professional development activities for personal as well as professional reasons. When undertaken in order to grow and become better at one's chosen field, professional development becomes a form of personal reward and enrichment. Those who practice it for individual motives usually improve job performance as much as those who engage in it for purely professional reasons.

\section{Traditional Professional Development Techniques}

There are many pathways to professional development. A librarian, throughout his or her career, may try several tacks, depending on individual needs, career goals, and amount and type of institutional support. Although it is not possible, or even desirable, to map out a single blueprint for professional development, one can identify its principal configurations.

In the most basic form of professional development, one keeps abreast of the journal literature and new publications in a field. Attending conferences and engaging in continuing education are other conventional forms. An integral part of any professional development plan is an analysis of one's own work profile, the identification of individual strengths and weaknesses to determine which skills can be built upon and which require 
improvement. Actively participating in a professional association or society constitutes a key element of professional development. Self-directed learning and in-service training are other essential activities. (Helmer, 1987) Informal collegial exchange, though not an organized activity, can contribute significantly to professional growth. More formal programs include taking part in visiting fellowships or job exchanges. Participating in a formal or informal mentoring relationship, either as a seasoned mentor or as a new professional, can contribute to the growth of both parties and to the profession as a whole. Research and writing are important elements of the professional development process. Scholarly research expands the knowledge base of a field, aids practitioners, benefits individual institutions and, above all, provides a forum for the discussion of major or controversial topics. (Pemberton, 1993) Finally, personal networking is an integral part of any professional development plan and is an irreplaceable means of growth and advancement (Lampton, 1989).

\section{Professional Development and the Internet}

The advent of worldwide connectivity, in which library patrons use sources well beyond the walls of the local library, is bringing about fundamental changes in the way we exercise our profession. Our professional development techniques need to evolve in a similar fashion. Many of the traditional techniques of professional development, outlined above, can be streamlined, expanded in scope, and speeded up by incorporating the Internet into the process.

For example, as electronic journals increase in number, the Internet becomes a vital tool in keeping abreast of current literature. Forthcoming publications are announced and products reviewed on electronic discussion groups, while abstracting services such as Current Cites render the task of keeping up with the literature infinitely simpler. By subscribing to electronic journals, discussion groups, and current awareness services, librarians extend the boundaries of the information they receive, while establishing filters to streamline the process and control the flow.

Continuingeducationassumes a differentform on the Internet, and librarians can take a variety of courses offered electronically. For example, the e-course "Let's Go Gopherin'," offered by Richard J. Smith and Jim Gerland in October/November 1993 as the third in a series of "Navigating the Internet" workshops, attracted over 17,000 subscribers from more than 50 countries.

Conference attendance, traditionally a cornerstone of professional development, is similarly facilitated as conferences become electronic and, in many cases, on-going. Participants in electronic conferences need not secure release time, travel to distant points, seek institutional support for funding, or incur the out-of-pocket expenses typical of traditional conference attendance.

Electronic mail has expanded the notion of collegial exchange. Now, librarians can converse with colleagues in the next office and in the next country with equal ease. Opportunities for personal networking abound. Through both e-mail and electronic discussion groups, the Internet provides access to experts and to expertise not readily available to those 'out of the loop' or to newcomers in the field. In posting material or asking for information on the network, librarians can receive responses from experts worldwide, and those responses may well come from a cross-section of professions, thereby broadening professional perspective substantially. Education librarians can choose from a large number of electronic discussion groups, newsletters, and journals, some peer-reviewed. (For listings of discussion groups and e-journals, see the Directory of Electronic Journals, Newsletters and Academic Discussion Lists by Michael Strangelove and Diane Kovacs, also available electronically.

Engaging in research is an important element of professional development. Electronic networking greatly enhances the research process, as the Internet opens up a world of resources to librarians from their desktops. Library catalogues and other databases can be searched and, in some cases, full-text sources retrieved almost instantaneously. Research costs, too, can be affected by the Internet. Software that a single researcher might find prohibitively expensive can be shared among several on the networks. Likewise, library consortiums can share database licensing costs, as groups of libraries band together to purchase joint access to databases for all consortium members.

The writing process is undergoing a similar metamorphosis in the electronic arena. Coauthors in distant locales can write in tandem, sending a piece of work back and forth across the network as they write and edit, and even submit the finished product for publication electronically.

Collegial feedback can also be solicited much more efficiently by electronic means. Stevan Harnad laments that "the written medium is hopelessly out of synch with the thinking mechanism" for lack of a capacity to "support the requisite rounds of feedback, in tempo giusto." (Harnad, 1991) The Internet provides that real-time medium. Using a technique called "scholarly skywriting" (Harnad, 1991) or posting workin-progress to an e-journal (e.g. Psycoloquy), and inviting commentary, an author can produce multiple versions of an article, reworking it at several reprises as feedback comes is, thus accelerating the give-and-take of scholarly discussion. Each successive version of the workcould then reposted electronically so that the document is actually 'published' numerous times. It may or may not appear in print in a final version. Those who have practiced scholarly skywriting report that these multiple exchanges enhanced their creativity. (Lemke, 1993)

In a recent 'net' article, Ann Okerson states that "it is well to remember that the ancestor of today's fancy scholarly journal was the diary or logbook (the original journal) in which the scholar or scientist recorded data, thought, ideas, meetings and conversations, much as do today's networked electronic lists." (Okerson,1991,p.18) She notes that some articles are discussed and debated on the net months before they appear in print. In this manner, not only can we see the progression in the development of thought, but we can choose to partake in it as it is happening. The ability to participate in the process of another's research and writing has not heretofore been possible to this degree.

The Internet is very rich in professional development sources for education librarians. The "subject tree" facility available at numerous gophersites (marvel.loc.gov or chico,rice.edu)points 
to important resources in education and in librarianship. Pathfinders such as J. Harris' Internet Resource Directory, David Riggins' Gopher Jewels, or T. Matthew Ciolek's Internet Voyager: Social Scientist's Guidebook... are invaluable. Thus, one can quickly identify the important gophers in the field of education or find easy links to large e-projects such as NYSERNet's Empire Schoolhouse Project, Carnegie Mellon's Internet in the Schools, or M.I.T.'s multi-user simulation environment MicroMUSE. Among bibliographic databases, the multidisciplinary CARL UnCover can be used not only to identify citations, a free service, but also to purchase full-text hardcopy for overnight delivery (telnet to pac.carl.org). Other important databases are ERIC for school library and some general library science journals in addition to education, and ERIC Digests, for full-text ERIC documents - both hosted by the University of Syracuse (gopher to spc.syr.edu) and accessible through other "gopher" pointers. Unique Internet services include AskERIC, an e-mail help and referral service sponsored by the ERIC Clearinghouse(e-mail to askeric@ericir.syr.edu)and BUBL, a bulletin board service for librarians (gopher to ukoln.bath.ac.uk 7070).

\section{Reshaping Professional Development for the Electronic Age}

"Education is in the midst of a monumental technological paradigm shift, one that will eventually change the way that all instructors teach and the way all students learn." (Jensen, 1993) Similarly, the Internet, with its ready access to worldwide resources, is reshaping the world in which librarians operate as well as many of their opportunities for professional growth. We too are in the midst of a 'paradigm shift.' Many of the traditional techniques of professional development converge onourdesktops. New possibilitics surface.

In the preceding section, we have seen how specific professional development techniques have been altered by the Internet. Now, let us look at ways in which some underlying attributes of professional development have been changed.

One of the most notable changes which the Internet brings to the professional development process is an opportunity for crossfertilization among many fields. The Internet helps to break down the barriers separating different fields, so that interaction is no longer limited to those in a single sphere. It allows for vast interconnections of people and ideas within a large group of disciplines. The Internet opens the meeting place to a much broader spectrum of people and a wealth of knowledge from many fields, thus adding an important new dimension to professional growth.

Distance learning takes on new meaning in cyberspace. Physical distances are bridged by electronic access measured in nanoseconds. While the Internet changes the way we conceive of space, it allows us to control our time in new ways too. Librarians can exchange e-mail messages or participate in electronic conferences at times of their own choosing. As these activities no longer depend on a fixed locale, they take place entirely at the individual participant's convenience. The Internet allows us to overcome some of the obstacles of space and time.

Traditionally, some professional developmentactivities have depended on strong institutional support in terms of release time and funding. (Havener, Stolt, 1994) Today, the availability of the Internet engenders less reliance on institutional support. Though helpful, support from one's institution is no longer requisite, as the Internet brings many professional development activities within the reach of everyone with a connection. Networking projects connect schools and libraries across the continent and beyond, and librarians enjoy an electronic learning community at their desks.

\section{Conclusion}

Although the Internet has not changed the fundamental definitions or goals of professional development, it has enhanced and facilitated techniques. Internet users are greatly empowered by the ability to learn, read, conduct research, write, network, teach, and attend conferences from the convenience of the desktop at low individual cost and at times of their choosing. Interactivity and "participative problem-solving"(Zuber-Skerritt, 1992) across space and in record time are the new order of the day. The Internet, with its flattened organizational structure, allows users to bridge physical distances, diverse subject fields, and myriad other barriers in order to access a host of information worldwide.

For education librarians, the internet opens possibilities of learning and research on a multinational and multi-dimensional scale that, in the past, was reserved for a privileged few. The potential for leaming and developing new skills from a single base is only beginning to be explored.

Many years ago, Marshall McLuhan was engaged in designing an 'Innovation Centre' at the Ontario Institute for Studies in Education (Toronto). In this centre, McLuhan aspired to create an environment, replete with the technological advantages of the time, where researchers could work, free of the temporal, spatial, and technological restraints of the usual workplace. The project came to a halt, for the resources necessary to realise McLuhan's vision did not yet exist. Today, the Internet may well be the prime innovative learning environment of our time.

\section{REFERENCES}

Chalofsky, N. (1992). A Unifying Definition for the Human Resource Development Profession. Human Resource Development Quarterly, 3, 175-182.

December, J. (1993, December). Information Sources: The Internet and Computer-Mediated Communication. [Online]. Available FTP: ftp.rpi.edu Directory:pub/communications File: internet-cmc

Dern, D.P. (1994). The Internet guide for new users. New York: McGraw-Hill. 
Gelfand, J. (1985). Professional Development for Reference and Adult Services Librarians. $R Q, 24,402-403$.

Harnad, S. (1991). Post-Gutenberg Galaxy: The Fourth Revolution in the Means of Production Knowledge. Public Access Computer Systems Review, 2, 39-53.

Harris, J. et.al Internet Resource Directory (education). [Online]. Available FTP: una.hh.lib.umich.edu Directory: inetdirsstacks Files: education:harris1, education:harris2, education:harris3, education:harris4.

Havener, M. \& Stolt, W. (1994). The professional development activities of academic librarians. Does institutional support make a difference? College and ResearchLibraries, 55, 2536.

Helmer, D. \& Mika, J.J. (1987). Continuing education: The pathway to professional development. Journal of Educational Media and Library Sciences, 24, 329-336.

Houle, C. (1980). Continuing Learning in the Professions. San Francisco: Jossey-Bass.

Jensen, R. (1993). The technology of the future is already here. CAUT Bulletin, 40, 14-15.

Kurman, T. (1992). Coping with change and computer lists. Illinois Libraries, 74, 506-508.

Lampton, W. (1989). Networking for personal and professional growth. Fund Raising Management, 20, 55-56.

Lemke, J. L. (1993) Education, cyberspace and change. [Serial Publication Online]. Electronic Journal on Virtual Culture, $1,1-18$.

Oberg, L. (1993). COLLIB-L: Listservs in Library Communication. C\&RL News, 54, 632-634.

Okerson, A. (1991). The electronic journal: What, whence and when?. The Public Access Computer Systems Review, 2, 524.

Pemberton, M. (1993). A profession without professional literature. Records Management Quarterly, 27, 52-55.

Penn, M., Romano, J., \& Foat, D. (1988). The relationship between job satisfaction and burnout: A study of human service professionals. Administration in Mental Health, 15, 157-165.

Rauschenbach, T.(1992).Sind nur lehrerpedagogen? Disziplinare selbstvergewisserungen im horizont des wandels von Sozial und erziehungsberufen. Zeitschrift fur Pedagogik, 38, 385417.
Riggins, D. (1994, January). Gopher kewels. [Online]. Available GOPHER: cwis.scu.edu Menu: Other Gopher and Information Servers File: Gopher-Jewels.

Strangelove, M., \& Kovacs, D. (1993). Directory of electronic journals, newsletters and academic discussion lists (3rd ed.). Washington, DC: Association of Research Libraries.

Webb, S. (1992). Continuing professional development: The way forward. Information Management Report, 2, 14.

Yanoff, S. (1993, November). Special Internet connections. [Online] Available GOPHER: gopher.uwaterloo.ca Menu:

Electronic resources around the world/Guides to Internet services File: Special Internet Connections.

York, J. (1990). A Lifetime of ;earning. Best's Review (Property/ Casualty), 91, 75-76.

Zuber-Skerritt, O. (1992). Professional development in higher education. A theoretical framework for action research. Briston, PA: Taylor and Francis.

Vivienne Monty is Senior Libarian, Scott Library, York University, 203D York University, 4700 Keele St., North York, Ont. M3J 1P3.

P. Warren-Wenk is Assistant Reference Librarian, Frost Library, York University, 2275 Bayview Ave., Toronto, ON M4N 3M5. 